\title{
Predictors of Illness Severity in COVID-19 Cases in Saudi Arabia
}

\author{
Reem Al Dossary (D) \\ Amani Alnimr $\mathbb{D D}^{1}$ \\ Reem Aljindan' \\ Khaled R Alkharsah (D) \\ Ahmed K Al-Qurayn' \\ Obeid Eltreifi' \\ Feras A Alkuwaiti ${ }^{2}$ \\ Abdullah B Almashouf ${ }^{2}$ \\ Ahmed M Alsahlawi ${ }^{2}$ \\ Amal Alshammari ${ }^{3}$ \\ Dhoha Hudhaiah ${ }^{3}$ \\ Mohammed S Alshahrani (iD) ${ }^{4}$ \\ Huda Bukhari ${ }^{2}$ \\ 'Department of Microbiology, College of \\ Medicine, Imam Abdulrahman bin Faisal \\ University (IAU), Dammam, Saudi Arabia; \\ ${ }^{2}$ Department of Internal Medicine, \\ College of Medicine, Imam Abdulrahman \\ bin Faisal University (IAU), Dammam, \\ Saudi Arabia; ${ }^{3}$ Department of Medical \\ Laboratory, King Fahd Hospital of the \\ University, Imam Abdulrahman bin Faisal \\ University (IAU), Dammam, Saudi Arabia; \\ ${ }^{4}$ Department of Emergency Medicine, \\ King Fahd Hospital of the University, \\ Imam Abdulrahman bin Faisal University \\ (IAU), Dammam, Saudi Arabia
}

Correspondence: Reem Al Dossary

P.O Box: 1982, Dammam, 34221

Tel +9663330000 ext 35155

Email raaldossary@iau.edu.sa
Purpose: Multiple studies worldwide have reported the clinical and epidemiological features of coronavirus disease 2019 (COVID-19), with limited reports from the Middle East. This study describes the clinical and epidemiological features of COVID-19 cases in the Eastern Province of Saudi Arabia and identified factors associated with the severity of illness.

Patients and Methods: This was an observational study of 341 COVID-19 cases. These cases were reported in the first three months after the first case in the country was identified. Clinical and demographic data were analyzed and described to identify the effects of age, sex, and ethnicity on illness severity. In addition, the duration of viral shedding and cycle threshold $(\mathrm{Ct})$ values of real-time PCR were evaluated as predictors of severity.

Results: The median age was 45 years. Males were twice as likely to be infected than females $(p<0.0001)$. The duration of viral shedding ranged from 9 to 36 days. The most common clinical presentations include fever, shortness of breath, cough, myalgia, sore throat, vomiting, and headache. Critical cases were significantly higher in men (23\% vs $8.7 \%)$, senior adults ( $>65$ years), individuals of Bengali ethnicity, and in patients with comorbidities including diabetes, hypertension, and dyslipidemia $(\mathrm{p}=0.001)$. The case fatality rate was found to be $10 \%$. The fatality was significantly higher in males than females $(13.8 \%$ vs $2.6 \%)$, and in Asians (17.9\%) than Arabs (6\%) and Africans $(0)(p=0.002)$. No association was found between viral load, represented by the RT-PCR cycle threshold $(\mathrm{Ct})$ values, and severity of illness.

Conclusion: Age, sex, and ethnicity are important predictors of COVID-19 severity. The cycle threshold $(\mathrm{Ct})$ of the SARS-CoV-2 RT-PCR test cannot be used as a predictor of the criticality of illness.

Keywords: factors, ethnicity, $\mathrm{Ct}$ value, Arabs, virus shedding

\section{Introduction}

In late December 2019, a cluster of pneumonia of unknown etiology emerged in Wuhan, China ${ }^{1}$ that was believed to be a zoonotic disease ${ }^{2,3}$ linked to a local animal market. ${ }^{4} \mathrm{~A}$ few weeks later, the disease showed sustained transmissibility among humans $^{5}$ and the etiology was identified as a novel member of the Coronaviridae, later referred to as the severe acute respiratory syndrome coronavirus-2 (SARS$\mathrm{CoV}-2)$ due to its genetic homology $(82 \%)$ to the previously identified member of the coronavirus family, SARS-CoV. ${ }^{4}$ Soon after, the virus spread rapidly beyond China, signaling an impending pandemic. On January 30, 2019, the World Health Organization declared the novel coronavirus outbreak as a Public Health Emergency of International Concern (PHEIC). 
The disease caused by the virus was named the coronavirus disease-2019 (COVID-19). ${ }^{6}$ Individuals infected with SARS-CoV-2 may be asymptomatic. More commonly, individuals present with a wide spectrum of clinical manifestations, ranging from mild illness to life-threatening pneumonia with a median incubation period of 6.4 days. ${ }^{7}$ Symptomatic patients commonly present with fever, cough, fatigue, shortness of breath, ${ }^{8}$ and sometimes gastrointestinal manifestations such as diarrhea, anorexia, nausea, vomiting, and abdominal pain. ${ }^{9}$ Children have been shown to manifest milder features of the disease compared to adults. ${ }^{10}$ However, some studies have suggested an increase in the incidence of multisystem inflammatory disease in children with COVID-19. ${ }^{11,12}$ In addition, pregnant women and their newborns seem to be mildly affected by COVID-19 with no reports of teratogenicity or severe illness. ${ }^{13}$ On November 26, 2020, the World Health Organization indicated that COVID -19 cases exceeded 59.8 million cases. Furthermore, multiple studies demonstrated that the virus was gradually evolving ${ }^{14,15}$ and this genetic evolution was thought to impact the severity and infectivity of COVID-19. ${ }^{16,17}$

This study is the only study that described the epidemiological and clinical features of COVID-19 in the first 341 cases diagnosed at a university teaching hospital in the Eastern Province of Saudi Arabia over the first three months of the pandemic in the country. We identified the spectrum of clinical presentation in different age groups. Demographic data and comorbidities were also analyzed and correlated to identify predictors of severity and prognosis. Understanding and documenting the features of COVID-19 at the start of the spread of the pandemic in the kingdom is vital for better understanding of the effect of genetic evolution on the behavior of the virus, a story that must be told.

\section{Materials and Methods}

A combined retrospective and prospective single-centered observational study was conducted at a university teaching hospital with 550 beds that serve patients from the Eastern Province of Saudi Arabia, as assigned by the Ministry of Health during the first wave of the COVID-19 pandemic. This study described the epidemiological and clinical features of COVID-19 for the initial 341 SARS-CoV-2 confirmed cases in the hospital (March 10 - June 13, 2020).

During the study period, 3146 individuals were tested for SARS-CoV-2 infection using nucleic acid detection tests, of which 341 were positive. The indications for testing included clinical suspicion of symptomatic COVID-19, contact with confirmed cases, healthcare worker screening, and screening for all elective hospital admissions.

Testing for SARS-CoV-2 infection was performed using either the RealStar SARS-CoV-2 RT-PCR kit (Altona Diagnostics, Hamburg, Germany) or the Xpert Xpress SARS-CoV-2 kit (Cepheid, California, USA) according to the availability and following the manufacturer's recommendations. Samples from all positive cases were sent to the National Health Laboratory for confirmation. Cycle thresholds were retrieved from the designated software, as shown in the final report.

All laboratory-confirmed COVID-19 cases were included in this study. Clinical, demographic, and SARSCoV-2 test results for all patients were obtained from a computerized hospital data system. Patients were stratified by age into groups: infants ( $\leq 1$ year), children $(>1$ years -19 years), adults (20-65 years), and senior adults ( $>65$ years), for analysis according to the WHO classification. Patients were also grouped based on clinical presentation as described by the Saudi Ministry of Health into four groups: asymptomatic, mild to moderate, severe, and critical cases based on respiratory distress, oxygen requirements, and organ dysfunction. Moderate disease was defined by the presence of pneumonia. Severe cases were defined by respiratory rates measuring more than $30 / \mathrm{min}$ and $40 / \mathrm{min}$, in adults and children, respectively, or arterial oxygen levels less than $90 \%$. Critical cases were signified by the need for mechanical ventilation, or the occurrence of acute respiratory distress syndrome (ARDS), sepsis, or septic shock. ${ }^{18}$ Serial RT-PCR results were recorded for all confirmed cases that were followed up for clearance using a test-based strategy. Clearance duration was defined as the duration between the first positive RT-PCR and the first negative RT-PCR sample, when the negative sample was confirmed by another negative RT-PCR sample collected $\geq 24 \mathrm{~h}$ later.

\section{Statistical Analysis}

All data were tabulated using Microsoft Excel spreadsheets. Statistical analyses were performed using SPSS, version 24 (IBM Corp, Armonk, NY, USA). Multivariate linear regression analysis was first performed (Table 1), followed by post hoc analysis for each of the variables.

\section{Results}

\section{Epidemiological Features of COVID-19}

The total number of patients with laboratory-confirmed COVID-19 infections was 341 . The male-to-female ratio 
Table I Multivariate Analysis of the Age Groups and Disease Severity with Other Demographic and Clinical Variables

\begin{tabular}{|l|l|l|l|l|l|l|l|}
\hline & Value & F & $\begin{array}{l}\text { Hypothesis Degrees of } \\
\text { Freedom }\end{array}$ & $\begin{array}{l}\text { Error Degrees of } \\
\text { Freedom }\end{array}$ & Significance & $\begin{array}{l}\text { Partial Eta } \\
\text { Squared }\end{array}$ & $\begin{array}{l}\text { Observed } \\
\text { Power }\end{array}$ \\
\hline Age groups & 0.262 & 1.752 & 54.000 & 987.000 & 0.001 & 0.087 & 1.000 \\
Disease severity & 0.413 & 3.257 & 42.000 & 858.000 & 0.000 & 0.138 & 1.000 \\
\hline
\end{tabular}

was 2:1 $(225: 116)(\mathrm{p}<0.0001)$. The mean age of patients was $44.19 \pm 18.03$ years $($ median $=45$ years, range $=4$ months to 96 years). There was no significant difference in the mean age between men and women $(\mathrm{p}=0.958)$.

Regarding the mode of acquisition of infection, $67.2 \%$ of patients $(n=229)$ did not recall contact with a suspected or confirmed COVID-19 case, nor was there any clear epidemiological link with the source of infection. In contrast, $20.2 \%(n=69)$ reported positive household contact with COVID-19 cases, and 3.2\% $(\mathrm{n}=11)$ reported contact with suspected cases not confirmed by laboratory tests. Only $7.3 \%(n=25)$ and $2.1 \%(n=7)$ of patients reported positive contact at work or travel history, respectively.

The case fatality rate (CFR), which is the proportion of deaths among cases, was $10 \%(n=34)$. Male patients exhibited a higher mortality rate $(13.8 \%, \mathrm{n}=31)$ than their female counterparts $(2.6 \%, \mathrm{n}=3)$, and this difference was statistically significant $\left(\mathrm{Chi}^{2}=10.68\right.$, $\mathrm{p}=0.001)$. Furthermore, the CFR was higher among patients of Asian descent $(n=21,17.9 \%)$ than in Arabs $(\mathrm{n}=13,6 \%)$ and Africans $(\mathrm{n}=0)(\mathrm{p}=0.002)$. The mortality rate was highest among patients older than 65 years $(24.32 \%)$, followed by patients aged between 41 and 65 years $(12.84 \%)$.

\section{Clinical Features of COVID-19}

Of the 341 COVID-19 cases, 52 (15.2\%) were asymptomatic. Of the symptomatic cases, $153(44.9 \%)$ had mild to moderate disease, $74(21.7 \%)$ had severe disease, and 62 (18.2\%) were critically ill (Figure 1). Symptomatic patients presented with a wide variety of clinical manifestations, including systemic manifestations in the form of fever, headache, and myalgia, as well as respiratory symptoms, such as cough, shortness of breath, and rhinorrhea. Three patients reported a loss of smell and taste. Some patients also reported gastrointestinal manifestations, such as nausea, vomiting, anorexia, and diarrhea. Overall, the most common clinical features were fever, shortness of breath, cough, myalgia, vomiting, sore throat, and headache (Table 2).
All infant cases described in this study (5/5) showed fever, which was significantly higher in infants than in all other age groups.

COVID-19 was found to be more severe in males, senior adults, and patients of Bangladeshi nationality. On the contrary, the disease was less severe in women, infants, children, and individuals of Saudi and Egyptian nationalities (Table 3). Furthermore, patients with diabetes mellitus, hypertension, and dyslipidemia were more likely to have severe illnesses (Table 3). No significant association was found between bronchial asthma, heart disease, cancer, or sickle cell disease and COVID-19 severity (Table 3).

\section{Viral Shedding Dynamics and Predictors of Severe COVID-19}

Of the 341 cases, one hundred and thirty-five (39.6\%) confirmed cases underwent clearance following a testbased strategy, with other cases being followed on a timebased clearance. The duration of viral shedding ranged between 9 and 36 days, with a median of 13.5 days \pm 5.66 (Figure 2). The association between the duration of shedding and severity of illness was not possible because asymptomatic cases followed time-based clearance with no repeated testing. No association was found between the cycle threshold ( $\mathrm{Ct}$ values) of the Xpert Xpress SARSCoV2 test and the severity of illness (Figure 3 ).

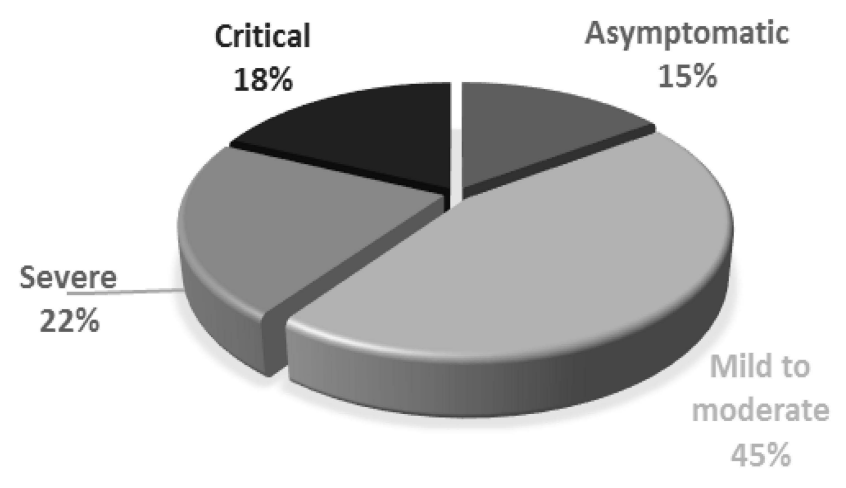

Figure I The spectrum of the severity of illness among the 34 I COVID-19 cases. 
Table 2 Clinical Features of COVID-19 Cases Between March and June 2020 According to Age Groups

\begin{tabular}{|c|c|c|c|c|c|c|c|c|c|c|}
\hline \multirow[t]{2}{*}{ Clinical Features } & \multicolumn{2}{|c|}{ Infant ( $\leq$ I Year) } & \multicolumn{2}{|c|}{ Children (>I-19 Years) } & \multicolumn{2}{|c|}{ Adults (>19-65) } & \multicolumn{2}{|c|}{ Senior Adults (65+) } & \multirow{2}{*}{$\begin{array}{l}\text { Total } \\
\mathbf{N}=341\end{array}$} & \multirow[t]{2}{*}{ P- value* } \\
\hline & $\mathbf{N}=5$ & $\%$ & $N=18$ & $\%$ & $\mathbf{N}=\mathbf{2 8 0}$ & $\%$ & $\mathbf{N}=38$ & $\%$ & & \\
\hline Fever & 5 & 2.16 & 12 & 5.19 & 189 & 81.82 & 25 & 10.82 & 231 & 0.296 \\
\hline Shivering & 0 & 0.00 & 0 & 0.00 & 22 & 95.65 & I & 4.35 & 23 & 0.936 \\
\hline Shortness of Breath & 2 & 1.31 & 4 & 2.61 & 127 & 83.01 & 20 & 13.07 & 153 & 0.106 \\
\hline Chest pain & 0 & 0.00 & I & 7.14 & 12 & 85.71 & I & 7.14 & 14 & 0.598 \\
\hline Wheezes & 0 & 0.00 & 0 & 0.00 & 3 & 75.00 & 1 & 25.00 & 4 & 0.683 \\
\hline Cough & I & 0.53 & 6 & 3.19 & 158 & 84.04 & 23 & 12.23 & 188 & 0.038 \\
\hline Sputum production & 0 & 0.00 & 0 & 0.00 & 17 & 80.95 & 4 & 19.05 & 21 & 0.179 \\
\hline Hemoptysis & 0 & 0.00 & 1 & 25.0 & 2 & 50.00 & 1 & 25.00 & 4 & 0.511 \\
\hline Rhinorrhea & 0 & 0.00 & 3 & 30.0 & 6 & 60.00 & I & 10.00 & 10 & 0.057 \\
\hline Loss of taste/smell & 0 & 0.00 & 0 & 0.00 & 3 & 100.00 & 0 & 0.00 & 3 & 0.470 \\
\hline Sore Throat & 0 & 0.00 & 3 & 9.68 & 26 & 83.87 & 2 & 6.45 & 31 & 0.336 \\
\hline Headache & 0 & 0.00 & 3 & 10.00 & 24 & 80.00 & 3 & 10.00 & 30 & 0.576 \\
\hline Myalgia & 0 & 0.00 & 3 & 5.56 & 41 & 75.93 & 10 & 18.52 & 54 & 0.122 \\
\hline Vomiting & 0 & 0.00 & 4 & 11.76 & 30 & 88.24 & 0 & 0.00 & 34 & 0.035 \\
\hline Diarrhea & I & 2.63 & 1 & 2.63 & 32 & 84.21 & 4 & 10.53 & 38 & 0.823 \\
\hline Abdominal pain & 0 & 0.00 & 1 & 14.29 & 6 & 85.71 & 0 & 0.00 & 7 & 0.168 \\
\hline Nausea & 0 & 0.00 & 0 & 0.00 & 7 & 77.78 & 2 & 22.22 & 9 & 0.376 \\
\hline Anorexia & 0 & 0.00 & 0 & 0.00 & I & 16.67 & 5 & 83.33 & 6 & $<0.001$ \\
\hline
\end{tabular}

Note: *Significance is defined as $p<0.05$.

\section{Discussion}

This study of the first COVID-19 cases diagnosed in a university teaching hospital in eastern Saudi Arabia showed that out of 3146 individuals tested for SARSCoV-2, 341 were positive. The overall detection rate was $10.8 \%$. The majority of COVID-19 cases were detected in adults (aged 19-65 years), followed by senior adults ( $>65$ years), which most probably reflects the frequency of COVID-19 diagnosis in the described settings rather than the incidence in various age groups. Furthermore, males were more commonly affected than females, which is consistent with a recent multivariate analysis study that identified male sex as an independent risk factor for the acquisition of COVID-19 infection. ${ }^{19}$ However, this could also be attributed to local social factors, with males being more exposed by leaving homes to work and family commitments during the lockdown periods.

The mode of acquisition was not known in most cases, indicating the huge impact of asymptomatic spreaders of the disease and the need to improve contact tracing measures in Saudi Arabia. This may also indicate the possibility of contracting the virus through means other than close contacts, such as long-distance migrating micro-aerosols. Such transmission is gaining growing acceptance among experts in the field. ${ }^{20}$ Our results support this mode of transmission as only one-fifth of our cases reported household contact with COVID-19 confirmed cases and only $3 \%$ reported contact with suspected cases. Population-level studies are still limited, and most data regarding the source of infection available to date represent specific institutional experiences.

The case fatality rate (CFR) was found to be $10 \%$, which is double that reported from Wuhan, China (5.6\%). ${ }^{21}$ There could be multiple reasons for the higher CFR, including the study setting. Our study involved a university hospital that was authorized to receive COVID-19 cases from other regional hospitals. This may lead to selection bias in the severity of cases included. Heterogeneity in ethnicity and other demographics may have also contributed to this difference. Importantly, the fatality rate does not take into consideration all individuals affected by SARS-CoV2 but only those who presented for testing (symptomatic individuals, contacts with known cases, or healthcare workers). This is also evident by the proportion of asymptomatic cases $(15.2 \%)$ in our cohort, which is less than that described in many similar studies. ${ }^{22}$ Thus, the overall infection mortality rate among individuals with COVID-19 infections is likely to be considerably lower. It has been estimated by the CDC and WHO to be around $0.5 \%$ $1 \% .{ }^{23,24}$ On the other hand, the reported case fatality rates may have been underestimated considering that fatal COVID-19 infections may remain undiagnosed. ${ }^{25}$ 
Table 3 The Distribution of COVID-19 Cases Based on Gender, Age, Co-Morbidities, and Nationality Relative to the Disease Severity

\begin{tabular}{|c|c|c|c|c|c|c|c|c|c|c|}
\hline \multirow[t]{2}{*}{ Variables } & \multicolumn{2}{|c|}{ Asymptomatic } & \multicolumn{2}{|c|}{ Mild to Moderate } & \multicolumn{2}{|c|}{ Severe } & \multicolumn{2}{|c|}{ Critical } & \multirow[t]{2}{*}{ Total } & \multirow[t]{2}{*}{ p-value* } \\
\hline & N 52 & $\%$ & N I53 & $\%$ & N 74 & $\%$ & N 62 & $\%$ & & \\
\hline \multicolumn{11}{|l|}{ Gender } \\
\hline Female & 22 & 19.30 & 60 & 52.63 & 22 & 19.30 & 10 & 8.77 & 114 & $<0.001$ \\
\hline Male & 29 & 12.83 & 93 & 41.15 & 52 & 23.01 & 52 & 23.01 & 226 & \\
\hline \multicolumn{11}{|l|}{ Age groups } \\
\hline Infant (=<lyear) & 2 & 40.00 & 2 & 40.00 & 1 & 20.00 & 0 & 0.00 & 5 & 0.08 \\
\hline Children (>I-19 years) & 4 & 21.05 & 12 & 63.16 & 3 & 15.79 & 0 & 0.00 & 19 & 0.017 \\
\hline Adults (>19-65) & 43 & 15.36 & 128 & 45.71 & 59 & 21.07 & 50 & 17.86 & 280 & 0.52 \\
\hline Senior adults $(>65)$ & 3 & 8.11 & 11 & 29.73 & 11 & 29.73 & 12 & 32.43 & 37 & 0.004 \\
\hline \multicolumn{11}{|l|}{ Co-morbidity } \\
\hline Diabetes Mellitus & 4 & 4.04 & 26 & 26.26 & 32 & 32.32 & 37 & 37.37 & 99 & $<0.001$ \\
\hline Hypertension & 5 & 6.17 & 23 & 28.40 & 32 & 39.51 & 21 & 25.93 & 81 & $<0.001$ \\
\hline Smoking & 0 & 0.00 & 1 & 20.00 & 3 & 60.00 & 1 & 20.00 & 5 & 0.23 \\
\hline Heart Failure & 1 & 12.50 & 2 & 25.00 & 5 & 62.50 & 0 & 0.00 & 8 & 0.96 \\
\hline Cancer & I & 16.67 & 3 & 50.00 & 0 & 0.00 & 2 & 33.33 & 6 & 0.97 \\
\hline Dyslipidemia & I & 3.23 & 8 & 25.81 & 12 & 38.71 & 10 & 32.26 & 31 & $<0.001$ \\
\hline CAD & 1 & 14.29 & 4 & 57.14 & 1 & 14.29 & 1 & 14.29 & 7 & 0.55 \\
\hline CKD & 5 & |4.7| & 8 & 23.53 & 8 & 23.53 & 12 & 35.29 & 34 & 0.23 \\
\hline Bronchial Asthma & 0 & 0.00 & 4 & 57.14 & 3 & 42.86 & 0 & 0.00 & 7 & 0.84 \\
\hline SCD & 0 & 0.00 & 4 & 80.00 & 1 & 20.00 & 0 & 0.00 & 5 & 0.44 \\
\hline \multicolumn{11}{|l|}{ Nationality } \\
\hline Saudi & 37 & 19.9 & 93 & 50.0 & 36 & 19.4 & 20 & 10.8 & 186 & $<0.001$ \\
\hline Bahraini & 0 & 0.0 & 0 & 0.0 & 1 & 100.0 & 0 & 0.0 & 1 & - \\
\hline Egyptian & 7 & 43.8 & 4 & 25.0 & 4 & 25.0 & 1 & 6.3 & 16 & 0.025 \\
\hline Jordanian & 0 & 0.0 & 0 & 0.0 & 0 & 0.0 & 2 & 100.0 & 2 & 0.05 \\
\hline Yemeni & 1 & II.I & 4 & 44.4 & 1 & II.I & 3 & 33.3 & 9 & 0.56 \\
\hline Bengali & 2 & 5.1 & 8 & 20.5 & 12 & 30.8 & 17 & 43.6 & 39 & $<0.001$ \\
\hline Indian & I & 2.5 & 23 & 57.5 & 7 & 17.5 & 9 & 22.5 & 40 & 0.26 \\
\hline Pakistani & 0 & 0.0 & 10 & 52.6 & 4 & 21.1 & 5 & 26.3 & 19 & 0.18 \\
\hline Philippine & 3 & 13.6 & 8 & 36.4 & 8 & 36.4 & 3 & 13.6 & 22 & 0.8 \\
\hline Somalian & 0 & 0.0 & I & 100.0 & 0 & 0.0 & 0 & 0.0 & 1 & - \\
\hline Sudanese & I & 20.0 & 1 & 20.0 & 1 & 20.0 & 2 & 40.0 & 5 & 0.52 \\
\hline
\end{tabular}

Note: *Significance is defined as $\mathrm{p}<0.05$

Abbreviation: SCD, sickle cell disease.

In our study, case fatality was significantly higher among males, which can be explained by a possible genetic predisposition and justified by the random and heterogeneous nature of the study sample. In contrast, nationality was a significant confounding factor similar to earlier reports. ${ }^{25,26} \mathrm{In}$ addition, fatality was also found to be affected by age. Higher fatality rates were detected in the older age groups. By ethnicity, fatality was higher in Asians, particularly Bengalis, compared to Arabs (17.9\% to $6 \%)(p=0.002) .{ }^{27}$ Similarly, the risk of severe disease and mortality has been shown to be higher in the African
American population in the United States, and attributed to the disproportional social determinants of health. ${ }^{28-30}$ The impact of racial and ethnic disparities has been a concern during the COVID-19 pandemic. This is evident among healthcare workers (HCWs), who are at higher risk of acquiring the infection due to the nature of their jobs. ${ }^{31,32}$ For instance, Hispanics constitute $17.6 \%$ of the total workforce in the United States, but they represent $25 \%$ of the healthcare aides who directly face continuous exposure. ${ }^{33}$ Furthermore, living conditions, including air pollution, overcrowding, and delayed access to medical 


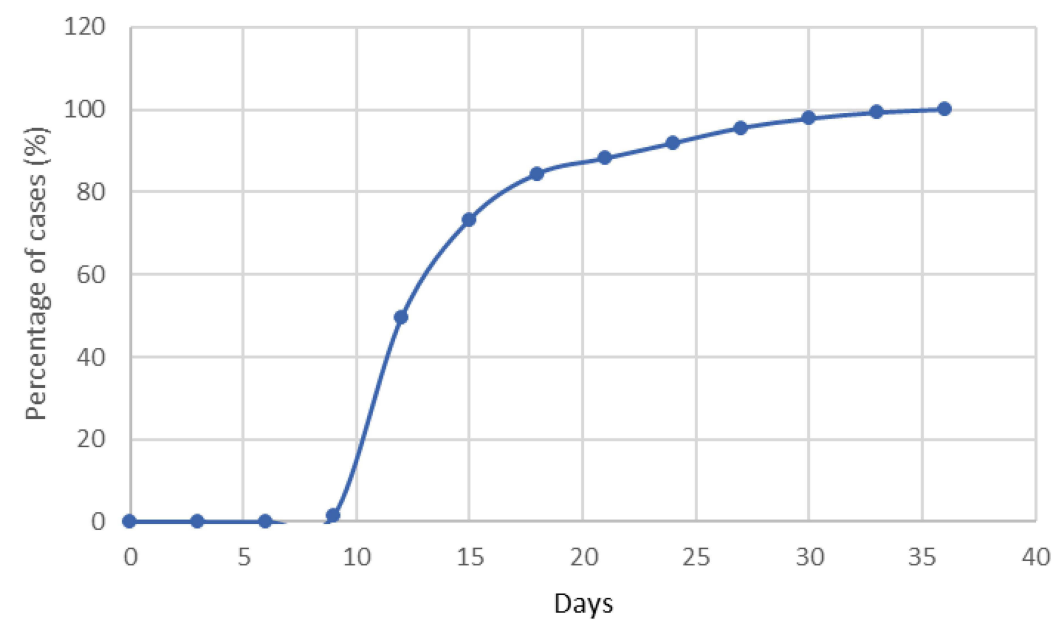

Figure 2 Dynamics of SARS-CoV2 viral clearance of 135 cases based on SARS-CoV-2 RNA detection.

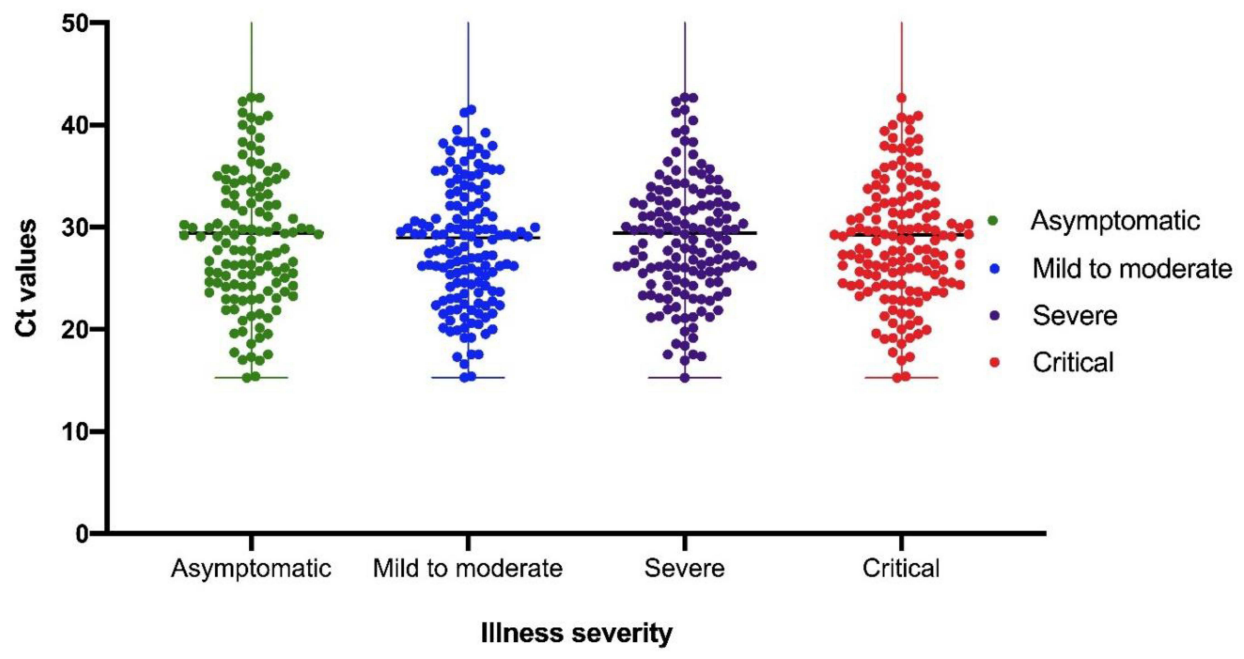

Figure 3 Frequency of cycle threshold $(C t)$ values for the $E$ and N2 gene targets relative to COVID-19 severity (P value 0.65$)$.

care among socially disadvantaged groups may contribute to this finding. ${ }^{34,35}$

Clinically, COVID-19 confirmed patients were classified into four categories based on the local national protocol. ${ }^{18}$ The categories included asymptomatic, mild to moderate, severe, and critical. This classification was based on clinical features, evidence of pneumonia, oxygen requirements, and the presence of serious complications. In addition to respiratory symptoms, patients also reported gastrointestinal symptoms, such as vomiting, diarrhea, abdominal pain, nausea, and anorexia, which is in line with reports from different countries. ${ }^{36}$ Fever was also significantly associated with age. In particular, fever was reported in $100 \%$ of infants, a feature that has been well documented in other studies. ${ }^{37}$ It is interesting that only three patients reported a lack of smell/taste in the study. Whether this is a feature of the disease in the region or a lack of reporting requires further investigation.

The severity of COVID-19 was significantly associated with male sex, senior adult age group, and Bengali ethnicity. Saudis and Egyptians (Arab ethnic groups) demonstrated a significantly lower severity of illness compared to the other groups. The severity of the disease in various patient populations needs to be interpreted with caution, taking into account the full burden of the pandemic, including delayed care and social determinants of health. Severity is also affected by comorbidities, particularly diabetes mellitus, hypertension, and dyslipidemia, as found in other studies. ${ }^{38}$ 
The cycle threshold $(\mathrm{Ct})$ refers to the number of cycles in a PCR assay required to amplify viral nucleic acids to a detectable level. To the best of our knowledge, no clinical studies have validated the use of $\mathrm{Ct}$ to estimate the disease burden of COVID-19. Although the cycle threshold ( $\mathrm{Ct}$ value) of the RT-PCR has often been considered a surrogate semi-quantitative measure for viral load estimation, ${ }^{39}$ the correlation between the period of infectivity and culture positivity was not verified, and isolation of the virus from clinical samples was possible even in patients with high $\mathrm{Ct}$ values, indicating that infectivity does not correlate with $\mathrm{Ct}$ values. ${ }^{40,41}$ In our study, the initial $\mathrm{Ct}$ value on presentation did not correlate with the severity of illness, which concurred with other studies. ${ }^{42}$ This can be attributed to variability in the timing of sample collection concerning the onset of clinical features, since many cases with severe illness commonly present late. In contrast, asymptomatic contacts commonly present within a few days of exposure and demonstrate variable $\mathrm{Ct}$ values. ${ }^{42}$ Furthermore, the $\mathrm{Ct}$ values are not standardized across various diagnostic platforms. Therefore, results cannot be compared between different assays. Given the uncertainty of the role of $\mathrm{Ct}$ values in estimating the relative viral RNA level in a specimen, our study does not support its use for guiding clinical decisions.

The minimum duration for viral clearance from respiratory samples in our cohort was 9 days, and the maximum reported duration was 36 days. The duration of viral shedding has been reported to be variable and influenced by the severity of the illness. ${ }^{43-46}$ Nevertheless, detectable viral RNA does not necessarily correlate with the presence of live infectious virus, as more accumulative evidence suggests that viral RNA detected after 8 days is unlikely to be infectious. ${ }^{43}$ Additionally, the virus has been detected in other types of specimens even after respiratory clearance, although this is unlikely to be of clinical or infection control significance. ${ }^{47,48}$ Therefore, time-based strategies for clearance have been widely adopted in various institutions. Nonetheless, recent reports have described viral transmission 10 days later from severely infected patients. Therefore, caution should be considered in vulnerable patient populations. ${ }^{44,49}$ Further data are needed to conclude the period of infectivity in cases of critical and severe illness.

Our study is not without limitations. Nevertheless, it contributes to the growing evidence of variable COVID-19 presentation and illness severity in relation to other factors and provides insight into the usefulness of $\mathrm{Ct}$ values as a predictive clinical tool.

\section{Conclusion}

Patients with COVID-19 manifest a wide range of clinical presentations, ranging from asymptomatic infection to severe and critical cases. Adult males were found to be twice as affected as females. The severity of COVID-19 was significantly associated with male sex, senior age group, and Asian ethnicity, particularly Bengali ethnicity. On the other hand, for the first time, milder forms of the disease were found to be significantly associated with Arab ethnic groups (Saudi and Egyptian), demonstrating the impact of ethnicity on disease severity. Furthermore, CFR was also found to be three times higher in Asians than in Arabs. The cycle threshold $(\mathrm{Ct})$ of Xpert Xpress SARS-CoV2, a surrogate measure of viral load, was not found to correlate with the severity of illness and therefore, is not recommended for use as a predictor tool.

\section{Data Sharing Statement}

All data analyzed in the study are available upon reasonable request from the corresponding author.

\section{Ethics Approval and Informed Consent}

Ethical approval for the study was obtained from the Institutional Review Board at Imam Abdulrahman Bin Faisal University (IRB-2020-01-150). Written patient consent was not requested by the IRB committee due to the retrospective nature of the study and that no patients identifiable information is presented. Patients' confidentiality in maintained throughout the study and the study doesn't carry any additional risk to patients. Furthermore, participation in the study did not interfere with patients management and all investigations included and analyzed were part of patients management as per the hospital protocols.

\section{Acknowledgments}

The research team is grateful to the Deanship of Scientific Research at Imam Abdulrahman Bin Faisal University for funding the project and to the Information Technology Department and the Department of Laboratory Medicine at King Fahd Hospital of the university for their cooperation in data acquisition, data collection, and curation. 


\section{Funding}

This project was approved and funded by the Deanship of Scientific Research at Imam Abdulrahman bin Faisal University (project number: covid-19-2020-021).

\section{Disclosure}

The authors report no conflicts of interest in this work.

\section{References}

1. Zhu N, Zhang D, Wang W, et al. A novel coronavirus from patients with pneumonia in China, 2019. $N$ Engl J Med. 2020;382 (8):727-733. doi:10.1056/NEJMoa2001017

2. Zhou P, Yang XL, Wang XG, et al. A pneumonia outbreak associated with a new coronavirus of probable bat origin. Nature. 2020;579 (7798):270-273. doi:10.1038/s41586-020-2012-7

3. Ji W, Wang W, Zhao X, Zai J, Li X. Cross-species transmission of the newly identified coronavirus 2019-nCoV. J Med Virol. 2020;92 (4):433-440. doi:10.1002/jmv.25682

4. Chan JF, Kok KH, Zhu Z, et al. Genomic characterization of the 2019 novel human-pathogenic coronavirus isolated from a patient with atypical pneumonia after visiting Wuhan. Emerg Microbes Infect. 2020;9(1):221-236. doi:10.1080/22221751.2020.1719902

5. Chan JF, Yuan S, Kok KH, et al. A familial cluster of pneumonia associated with the 2019 novel coronavirus indicating person-toperson transmission: a study of a family cluster. Lancet. 2020;395 (10223):514-523. doi:10.1016/S0140-6736(20)30154-9

6. Dong L, Li Z, Fung ICH. A call for consistency in the official naming of the disease caused by severe acute respiratory syndrome Coronavirus 2 in non-English languages. Disaster Med Public Health Prep. 2020;14:e25-e26.

7. Backer JA, Klinkenberg D, Wallinga J. Incubation period of 2019 novel coronavirus (2019-nCoV) infections among travellers from Wuhan, China, 20-28 January 2020. Euro Surveill. 2020;25(5). doi:10.2807/1560-7917.ES.2020.25.5.2000062

8. Huang C, Wang Y, Li X, et al. Clinical features of patients infected with 2019 novel coronavirus in Wuhan, China. Lancet. 2020;395 (10223):497-506. doi:10.1016/S0140-6736(20)30183-5

9. Tian Y, Rong L, Nian W, He Y. Review article: gastrointestinal features in COVID-19 and the possibility of faecal transmission. Aliment Pharmacol Ther. 2020;51(9):843-851. doi:10.1111/ apt. 15731

10. Song W, Li J, Zou N, Guan W, Pan J, Xu W. Clinical features of pediatric patients with coronavirus disease (COVID-19). J Clin Virol. 2020;127:104377. doi:10.1016/j.jcv.2020.104377

11. Toubiana J, Poirault C, Corsia A, et al. Kawasaki-like multisystem inflammatory syndrome in children during the covid-19 pandemic in Paris, France: prospective observational study. BMJ. 2020;369: m2094. doi:10.1136/bmj.m2094

12. Rauf A, Vijayan A, John ST, Krishnan R, Latheef A. Multisystem inflammatory syndrome with features of atypical Kawasaki disease during COVID-19 pandemic. Indian J Pediatr. 2020;87(9):745-747. doi:10.1007/s12098-020-03357-1

13. Yang H, Sun G, Tang F, et al. Clinical features and outcomes of pregnant women suspected of coronavirus disease 2019. J Infect. 2020;81(1):e40-e44. doi:10.1016/j.jinf.2020.04.003

14. World Health Organization. Coronavirus disease (COVID-19); 2020. Available from: https://www.who.int/docs/default-source/coronavir use/situation-reports/20200921-weekly-epi-update-6.pdf?sfvrsn= d9cf9496_4. Accessed October 1, 2021.

15. Phan T. Genetic diversity and evolution of SARS-CoV-2. Infect Genet Evol. 2020;81:104260. doi:10.1016/j.meegid.2020.104260
16. Biswas SK, Mudi SR. Genetic variation in SARS-CoV-2 may explain variable severity of COVID-19. Med Hypotheses. 2020;143:109877. doi:10.1016/j.mehy.2020.109877

17. Hoehl S, Ciesek S. The virology of SARS-CoV-2. Internist. 2020;61 (8):789-792. doi:10.1007/s00108-020-00853-6

18. Ministry of Health. Saudi MoH protocol for patients suspected of/ confirmed with COVID-19 version 2.1; 2020. Available from: https:// www.moh.gov.sa/Ministry/MediaCenter/Publications/Documents/ $\mathrm{MOH}$-therapeutic-protocol-for-COVID-19.pdf. Accessed October 1, 2021.

19. de Lusignan S, Dorward J, Correa A, et al. Risk factors for SARS-CoV-2 among patients in the Oxford Royal College of General Practitioners Research and Surveillance Centre primary care network: a cross-sectional study. Lancet Infect Dis. 2020;20 (9):1034-1042. doi:10.1016/S1473-3099(20)30371-6

20. Baud D, Qi X, Nielsen-Saines K, Musso D, Pomar L, Favre G. Real estimates of mortality following COVID-19 infection. Lancet Infect Dis. 2020;20(7):773. doi:10.1016/S1473-3099(20)30195-X

21. Oran DP, Topol EJ. Prevalence of asymptomatic SARS-CoV-2 infection: a narrative review. Ann Intern Med. 2020;173(5):362-367. doi:10.7326/M20-3012

22. World Health Organization. COVID-19 pandemic planning scenarios; 2020. Available from: https://www.cdc.gov/coronavirus/2019-ncov /hcp/planning-scenarios.html. Accessed October 1, 2021.

23. CDC. Estimating mortality from COVID-19; 2020. Available from: https://www.who.int/publications/i/item/WHO-2019-nCoV-Sci-BriefMortality-2020.1. Accessed October 1, 2021.

24. Weinberger DM, Chen J, Cohen T, et al. Estimation of excess deaths associated with the COVID-19 pandemic in the United States, March to May 2020. JAMA Intern Med. 2020;180(10):1336. doi:10.1001/ jamainternmed.2020.3391

25. Kragholm K, Andersen MP, Gerds TA, et al. Association between male sex and outcomes of Coronavirus disease 2019 (Covid-19) a Danish nationwide, register-based study. Clin Infect Dis. 2020. doi:10.1093/cid/ciaa924

26. Suleyman G, Fadel RA, Malette KM, et al. Clinical characteristics and morbidity associated with Coronavirus disease 2019 in a series of patients in metropolitan detroit. JAMA Netw Open. 2020;3(6): e2012270. doi:10.1001/jamanetworkopen.2020.12270

27. Bonanad C, Garcia-Blas S, Tarazona-Santabalbina F, et al. The effect of age on mortality in patients with COVID-19: a meta-analysis with 611,583 subjects. J Am Med Dir Assoc. 2020;21(7):915-918. doi:10.1016/j.jamda.2020.05.045

28. Rimmer A. Covid-19: two thirds of healthcare workers who have died were from ethnic minorities. BMJ. 2020;369:m1621. doi:10.1136/bmj.m1621

29. Hughes MM, Groenewold MR, Lessem SE, et al. Update: characteristics of health care personnel with COVID-19 - United States, February 12-July 16, 2020. Morb Mortal Wkly Rep. 2020;69 (38):1364-1368. doi:10.15585/mmwr.mm6938a3

30. Kambhampati AK, O'Halloran AC, Whitaker M, et al. COVID-19associated hospitalizations among health care personnel - COVIDNET, 13 States, March 1-May 31, 2020. MMWR Morb Mortal Wkly Rep. 2020;69(43):1576-1583. doi:10.15585/mmwr.mm6943e3

31. Tai DBG, Shah A, Doubeni CA, Sia IG, Wieland ML. The disproportionate impact of COVID-19 on racial and ethnic minorities in the United States. Clin Infect Dis. 2021;72(4):703-706. doi:10.1093/cid/ ciaa815

32. Karaca-Mandic P, Georgiou A, Sen S. Assessment of COVID-19 hospitalizations by race/ethnicity in 12 states. JAMA Intern Med. 2021;181(1):131-134. doi:10.1001/jamainternmed.2020.3857

33. 2018 American Community Survey -yS. Hispanic Americans in healthcare and in essential roles new American economy; 2020. Available from: https://research.newamericaneconomy.org/report/hispanicamericans-in-healthcare-and-in-essential-roles/. Accessed October 1, 2021. 
34. Chowkwanyun M, Reed AL. Racial health disparities and Covid-19 caution and context. $N$ Engl $J$ Med. 2020;383(3):201-203. doi:10.1056/NEJMp2012910

35. Webb Hooper M, Napoles AM, Perez-Stable EJ. COVID-19 and racial/ethnic disparities. JAMA. 2020;323(24):2466-2467. doi:10.1001/jama.2020.8598

36. Deidda S, Tora L, Firinu D, et al. Gastrointestinal Coronavirus disease 2019: epidemiology, clinical features, pathogenesis, prevention and management. Expert Rev Gastroenterol Hepatol. 2021;15:41-50.

37. Christophers B, Marin BG, Oliva R, Powell WT, Savage TJ, Michelow IC. Trends in clinical presentation of children with COVID-19: a systematic review of individual participant data Pediatr Res. 2020. doi:10.1038/s41390-020-01161-3

38. Mantovani A, Byrne CD, Zheng MH, Targher G. Diabetes as a risk factor for greater COVID-19 severity and in-hospital death: a meta-analysis of observational studies. Nutr Metab Cardiovasc Dis. 2020;30(8):1236-1248. doi:10.1016/j.numecd.2020.05.014

39. Cevik M, Tate M, Lloyd O, Maraolo AE, Schafers J, Ho A. SARSCoV-2, SARS-CoV, and MERS-CoV viral load dynamics, duration of viral shedding, and infectiousness: a systematic review and meta-analysis. Lancet Microbe. 2021;2(1):e13-e22. doi:10.1016/ S2666-5247(20)30172-5

40. Aranha C, Patel V, Bhor V, Gogoi D. Cycle threshold values in RT-PCR to determine dynamics of SARS-CoV-2 viral load: an approach to reduce the isolation period for COVID-19 patients. J Med Virol. 2021. doi:10.1002/jmv.27206

41. Platten M, Hoffmann D, Grosser R, et al. SARS-CoV-2, CT-values, and infectivity - conclusions to be drawn from side observations. Viruses. 2021;13(8):1459. doi:10.3390/v13081459
42. Shah S, Singhal T, Davar N, Thakkar P. No correlation between $\mathrm{Ct}$ values and severity of disease or mortality in patients with COVID 19 disease. Indian J Med Microbiol. 2021;39(1):116-117. doi:10.1016/j. ijmmb.2020.10.021

43. Bullard J, Dust K, Funk D, et al. Predicting infectious SARS-CoV-2 from diagnostic samples. Clin Infect Dis. 2020;71(10):2663-2666. doi:10.1093/cid/ciaa638

44. Liu WD, Chang SY, Wang JT, et al. Prolonged virus shedding even after seroconversion in a patient with COVID-19. J Infect. 2020;81 (2):318-356.

45. Perera R, Tso E, Tsang OTY, et al. SARS-CoV-2 virus culture and subgenomic RNA for respiratory specimens from patients with mild Coronavirus disease. Emerg Infect Dis. 2020;26(11):2701-2704. doi:10.3201/eid2611.203219

46. Wolfel R, Corman VM, Guggemos W, et al. Virological assessment of hospitalized patients with COVID-2019. Nature. 2020;581 (7809):465-469. doi:10.1038/s41586-020-2196-x

47. Cheung KS, Hung IFN, Chan PPY, et al. Gastrointestinal manifestations of SARS-CoV-2 infection and virus load in fecal samples from a Hong Kong cohort: systematic review and meta-analysis. Gastroenterology. 2020;159(1):81-95. doi:10.1053/j.gastro.20 20.03.065

48. Zheng S, Fan J, Yu F, et al. Viral load dynamics and disease severity in patients infected with SARS-CoV-2 in Zhejiang province, China, January-March 2020: retrospective cohort study. BMJ. 2020;369: m1443. doi:10.1136/bmj.m1443

49. Jeong HW, Kim SM, Kim HS, et al. Viable SARS-CoV-2 in various specimens from COVID-19 patients. Clin Microbiol Infect. 2020;26 (11):1520-1524. doi:10.1016/j.cmi.2020.07.020
Infection and Drug Resistance

\section{Publish your work in this journal}

Infection and Drug Resistance is an international, peer-reviewed openaccess journal that focuses on the optimal treatment of infection (bacterial, fungal and viral) and the development and institution of preventive strategies to minimize the development and spread of resistance. The journal is specifically concerned with the epidemiology of antibiotic resistance and the mechanisms of resistance development and diffusion in both hospitals and the community. The manuscript management system is completely online and includes a very quick and fair peerreview system, which is all easy to use. Visit http://www.dovepress.com/ testimonials.php to read real quotes from published authors. 